\title{
PI3K/mTOR inhibition can impair tumor invasion and metastasis in vivo despite a lack of antiproliferative action in vitro: implications for targeted therapy
}

\author{
Seth A. Wander $\cdot$ Dekuang Zhao $\cdot$ Alexandra H. Besser $\cdot$ Feng Hong $\cdot$ \\ Jianqin Wei - Tan A. Ince · Clara Milikowski $\cdot$ Nanette H. Bishopric · \\ Andy J. Minn $\cdot$ Chad J. Creighton $\cdot$ Joyce M. Slingerland
}

Received: 6 December 2012/ Accepted: 14 December 2012/Published online: 21 February 2013

(c) The Author(s) 2013. This article is published with open access at Springerlink.com

\begin{abstract}
Oncogenic PI3K/mTOR activation is frequently observed in human cancers and activates cell motility via 27 phosphorylations at T157 and T198. Here we explored the potential for a novel PI3K/mTOR inhibitor to inhibit tumor invasion and metastasis. An MDA-MB-231 breast cancer line variant, MDA-MB-231-1833, with high metastatic bone tropism, was treated with a novel catalytic PI3K/mTOR inhibitor, PF-04691502, at nM doses that did not impair proliferation. Effects on tumor cell motility, invasion, p27 phosphorylation, localization, and bone metastatic outgrowth were assayed. MDA-MB-231-1833 showed increased PI3K/mTOR activation, high levels of cytoplasmic p27pT157pT198 and increased cell motility and invasion in vitro versus parental. PF-04691502 treatment, at a dose that did not affect proliferation, reduced total and
\end{abstract}

Electronic supplementary material The online version of this article (doi:10.1007/s10549-012-2389-6) contains supplementary material, which is available to authorized users.

S. A. Wander $\cdot$ D. Zhao - A. H. Besser $\cdot$ F. Hong ·

T. A. Ince $\cdot$ J. M. Slingerland $(\bowtie)$

Braman Family Breast Cancer Institute at Sylvester, Miller

School of Medicine, University of Miami, Miami, FL 33136,

USA

e-mail: jslingerland@med.miami.edu

S. A. Wander - D. Zhao - A. H. Besser

S. and D. Fuente Graduate Program in Cancer Biology, Miami,

FL 33136, USA

J. Wei · N. H. Bishopric · J. M. Slingerland

Department of Medicine, U of Miami Miller School of

Medicine, Miami, FL 33136, USA

T. A. Ince - C. Milikowski

Department of Pathology, University of Miami, Miami, FL

33136, USA cytoplasmic p27, decreased p27pT157pT198 and restored cell motility and invasion to levels seen in MDA-MB-231. p27 knockdown in MDA-MB-231-1833 phenocopied PI3K/ mTOR inhibition, whilst overexpression of the phosphomimetic mutant p27T157DT198D caused resistance to the anti-invasive effects of PF-04691502. Pre-treatment of MDAMB-231-1833 with PF-04691502 significantly impaired metastatic tumor formation in vivo, despite lack of antiproliferative effects in culture and little effect on primary orthotopic tumor growth. A further link between cytoplasmic $\mathrm{p} 27$ and metastasis was provided by a study of primary human breast cancers which showed cytoplasmic p27 is associated with increased lymph nodal metastasis and reduced survival. Novel PI3K/mTOR inhibitors may oppose tumor metastasis independent of their growth inhibitory effects, providing a rationale for clinical investigation of $\mathrm{PI} 3 \mathrm{~K} / \mathrm{mTOR}$ inhibitors in settings to prevent micrometastasis. In primary human breast cancers, cytoplasmic p27 is associated with worse outcomes and increased nodal

\section{A. J. Minn}

Department of Radiation Oncology, Abramson Family Cancer

Research Institute, Perelman School of Medicine, University of Pennsylvania, Philadelphia, PA, USA

C. J. Creighton

Division of Biostatistics, Dan L. Duncan Cancer Center, Baylor College of Medicine, Houston, TX, USA

J. M. Slingerland

Department of Biochemistry \& Molecular Biology, University of Miami, Miami, FL 33136, USA 
metastasis, and may prove useful as a marker of both PI3K/ mTOR activation and PI3K/mTOR inhibitor efficacy.

Keywords p27 - PI3K/mTOR · Cancer invasion · Motility $\cdot$ Metastasis

\section{Introduction}

Mortality from breast and other cancers commonly results from metastasis to distant organs including the liver and lung; and bone metastasis can cause significant morbidity [1]. Until recently, the lack of knowledge of molecular mechanisms underlying metastasis has limited the development of therapies that target tumor spread. Characterization of pathways that drive metastasis may yield important new insights for better application of targeted therapies.

The PI3K/mTOR pathway is activated in a majority of human cancers through receptor tyrosine kinase activation or amplification, PTEN loss, and activating mutations of PIK3CA or other downstream effectors [2, 3]. The PI3K pathway activates two mTOR complexes, mTOR complex 1 (mTORC1) and mTORC2, both of which coordinate cell proliferation with nutrient availability via effects on many biosynthetic processes [4]. In cancers, PI3K/mTOR promotes cell survival and proliferation, and increasing data also implicate this pathway in tumor invasion and metastasis [2, 5]. ErbB2 overexpression has been shown to promote lung metastasis from orthotopic breast cancer xenografts via mTOR/Raptor-dependent $\mathrm{p} 70^{\mathrm{S} 6 \mathrm{~K}}$ activation, and activated $\mathrm{p} 70^{\mathrm{S} 6 \mathrm{~K}}$ in primary human breast cancers was correlated with increased metastasis [6]. Rictor [7] and mTORC2-dependent AKT activation [8] have been implicated in experimental lung metastasis. While increasing data implicate $\mathrm{PI} 3 \mathrm{~K} / \mathrm{mTOR}$ in tumor metastasis, mechanisms underlying this remain poorly defined.

The CDK-inhibitor, p27, plays well-established roles in cell cycle regulation, but has also been shown to have prooncogenic functions in cancer independent of its effects on the cell cycle [9]. As a nuclear CDK-inhibitor, p27 restrains normal cell growth, but in many cancers, constitutive $\mathrm{PI} 3 \mathrm{~K} / \mathrm{mTOR}$ activation drives kinases including AKT [10-12], SGK [13], and RSK [14, 15] to phosphorylate p27 at T157 and/or T198, which impairs nuclear p27 import [10] and leads to its accumulation in the cytoplasm. Cytoplasmic p27 increases cell motility by RhoA inhibition, disrupting actin cytoskeletal stability [16]. p27-RhoA binding is enhanced by p27 phosphorylation at T198 [14]. Evidence that pro-oncogenic effects of p27 were independent of CDK inhibition came from mice expressing p27 defective for cyclin-CDK binding (p27 ${ }^{\mathrm{CK}-}$ ). p2 $7^{\mathrm{CK}-/ \mathrm{CK}-}$ knock-in mice show multi-organ hyperplasia (a p27 null phenocopy), as well as cytoplasmic $\mathrm{p} 27^{\mathrm{CK}-}$ localization and spontaneous neoplasia [17]. Thus, oncogenic PI3K/ mTOR activation promotes cytoplasmic p27 accumulation, increased cell migration, and may contribute to neoplastic progression.

The frequent activation of PI3K/mTOR in human cancers has led to development of drugs that target these pathways. Rapamycin and first-generation rapalogs are allosteric inhibitors of mTORC1. With few exceptions, most notably in renal cell carcinoma and mantle cell lymphoma, these agents have showed limited efficacy as single agents in clinical trials due to incomplete substratespecific mTORC1 inhibition and the activation of numerous bypass pathways [3, 18]. This prompted development of second-generation catalytic site inhibitors that target PI3K, mTOR or both, many of which have shown promise in preclinical studies and early clinical trials [3]. Dual $\mathrm{PI} 3 \mathrm{~K} / \mathrm{mTOR}$ inhibitors have potent antiproliferative and pro-apoptotic effects in several human cancer xenograft models [19-22]. While most studies have evaluated drug efficacy against primary xenotumor growth, their ability to inhibit tumor metastasis, the major cause of cancer patient death, has not been systematically evaluated.

The present study provides in vivo evidence that $\mathrm{PI} 3 \mathrm{~K} /$ mTOR activity is critical for the metastatic process in a model of bone metastasis. The highly bone metastatic variant of the MDA-MB-231 breast cancer model, 1833 [23], showed PI3K/mTOR activation, high levels of p27pT157 and p27pT198, and p27-dependent motility/ invasion in vitro. The novel PI3K/mTOR catalytic site inhibitor, PF-04691502, reduced p27 phosphorylation and cytoplasmic accumulation, and impaired tumor cell invasion. Moreover, this drug effectively impaired outgrowth of bone metastases in vivo. p27CK-T157D/T198D transfection rendered cells resistant to inhibition of motility/invasion by the $\mathrm{PI} 3 \mathrm{~K} / \mathrm{mTOR}$ inhibitor, suggesting that the activity of PF-04691502 is mediated in part by its action on p27. These data implicate the PI3K/mTOR pathway as a key mediator of tumor metastasis and reveal a novel rationale for application of catalytic-site $\mathrm{PI} 3 \mathrm{~K} / \mathrm{mTOR}$ inhibitors in cancer therapy.

\section{Results}

Metastatic cells show PI3K/mTOR activation and resistance to antiproliferative effects of PI3K/ mTOR inhibition at nM PF-04691502 doses

To investigate the role of $\mathrm{PI} 3 \mathrm{~K} / \mathrm{mTOR}$ pathway activation in tumor cell invasion and metastasis, we used a well-characterized luciferase tagged MDA-MB-231 (hereafter 231) breast cancer line variant, MDA-MB-231-1833 (hereafter 
1833), that consistently shows greater bone metastasis than parental [23]. The 1833 cells demonstrated enhanced PI3K/ mTOR signaling relative to parental 231 , with activation of downstream kinases (Fig. 1a). PF-04691502 (hereafter PF1502) is a potent, catalytic inhibitor of both PI3K and mTOR kinases with antiproliferative effects at nanomolar doses in vitro, and potent anti-tumor effects on multiple xenografts in vivo [24]. Since drug-mediated loss of cell survival or proliferation would abrogate metastasis, drug levels were titrated to determine if effects on motility/invasion could be distinguished from antiproliferative actions. Treatment of both 231 and 1833 lines at $250 \mathrm{nM}$ concentration inhibited PI3K/mTOR effector kinase activities (Fig. 1a) but neither $48 \mathrm{~h}$ (top) nor 7 day (bottom) continuous drug exposures inhibited subsequent cell proliferation over the following week (Fig. 1b) nor did this drug dose inhibit cell cycle progression in either 231 or 1833 (Fig. 1c). Indeed both 231 and 1833 were resistant to growth arrest by PF1502 at drug doses that arrest other lines (see drug titration in BT-20, 231 and 1833, Fig. 1d). At 250 nM, PF1502 did not yield a sub-G1 fraction (Fig. 1d), nor did it reduce cell viability or induce caspase 3 cleavage (Fig. 1e).

PI3K/mTOR inhibition impairs tumor cell motility and invasion

Cellular adhesion as measured with the XCelligence RealTime Cell Analysis system (Fig. 2a and supplemental Fig S1), migration by wound-healing assay (Fig. 2b), and transwell matrigel invasion (Fig. 2c) were all decreased by pretreatment of both 231 and 1833 cells with $250 \mathrm{nM}$ PF1502 for $48 \mathrm{~h}$. The highly bone-metastatic 1833 cells showed enhanced migration and markedly enhanced invasion relative to parental 231 (Fig. 2b-c). Thus, PI3K/ mTOR inhibition, at a PF1502 dose that did not affect proliferation or survival, abolished the excess motility and invasion of 1833 over parental 231.

Increased cytoplasmic p27 in 1833 cells is reduced by PF1502 treatment

While nuclear p27 plays an established role to inhibit G1phase cell cycle progression, recent work has implicated cytoplasmic p27 in the promotion of cell motility [25]. $\mathrm{PI} 3 \mathrm{~K} / \mathrm{mTOR}$ effector kinases, including AKT, RSK, and SGK, phosphorylate C-terminal p27 residues T157 and T198 causing its accumulation in the cytoplasm [25]. The 1833 cells had higher total p27 levels, p27 phosphorylation at T157/T198 (Fig. 3a), and cytoplasmic p27 accumulation compared to parental 231 (Fig. 3b). While most pronounced in 1833, PF1502 (250 nM) decreased p27 T157/ T198 phosphorylation and reduced cytoplasmic p27 (Fig. 3a, b) in both lines. Notably, p27 knockdown in 1833 cells (Fig. 3c) reduced cell adhesion (Fig. 3d), and impaired motility and matrigel invasion to a similar extent as treatment with PF1502 (see Fig. 2b, c vs Fig. 3e, f). Thus, loss of p27 in 1833 cells phenocopied in vitro effects of PI3K/mTOR inhibition on cell adhesion, motility and invasion. In the parental 231 line that lacked high cytoplasmic p27 (Fig. 3b), p27 knockdown did not significantly affect motility and invasion.

\section{p27CK-T157DT198D confers partial PF1502 resistance}

If p27 critically mediates PI3K/mTOR effects on cell invasion, a p27 phosphomimetic mutant should oppose the PF1502-dependent reduction in motility and invasion. To test this, a phosphomimetic p27T157DT198D mutant defective for cyclin-CDK interaction (p27CK-T157DT198D, abbreviated p27CK-DD) was introduced into both 231 and 1833 cells (Fig. 4a). p27CK-DD increased 231 cell transwell motility, and 231p27CK-DD was resistant to inhibition of motility by PF1502 (Fig. 4b). Similarly, matrigel invasion by $231 \mathrm{p} 27 \mathrm{CK}-\mathrm{DD}$ was greater than that of parental 231 cells and was not significantly reduced by PF1502 (Fig. 4c). Introduction of p27CK-DD into 1833 cells - that already expressed high levels of cytoplasmic p27pT157pT198- did not significantly increase matrigel invasion. Notably, while PF1502 impaired invasion in 1833 (Fig. 2c), 1833p27 CK-DD cells were resistant to this effect (Fig. 4d). Thus, cytoplasmic p27pT157pT198 plays a key role in mediating $\mathrm{PI} 3 \mathrm{~K} / \mathrm{mTOR}$-dependent motility and invasion.

\section{$\mathrm{PI} 3 \mathrm{~K} / \mathrm{mTOR}$ inhibition reduces metastasis in vivo}

Given the marked effect of PF1502 to inhibit cell motility and invasion, we next assayed its effects on tumor metastasis in vivo. To test if prolonged $\mathrm{PI} 3 \mathrm{~K} / \mathrm{mTOR}$ inhibition in vitro would affect the subsequent ability to establish bone metastasis following intracardiac injection, cells were treated or not with PF1502 $250 \mathrm{nM}$ for $7 \mathrm{~d}$ followed by intracardiac injection into nude mice ( $n=10$ /group). Animals received no further drug thereafter. These assays did not aim to test anti-tumor effects per se but whether PI3K/mTOR activity at the time of injection was required for manifestation of the metastatic phenotype. Viable tumor burden was quantitated by in vivo imaging system (IVIS) of tumor bioluminescence and representative IVIS images, graphs of photon flux over time and at the end of the experiment, and bone metastasis histopathology are shown in Fig. 5a-d. Untreated 1833 gave rise to more bone metastases than did 231 over 3 weeks, as expected [23]. While seven days of $250 \mathrm{nM}$ PF1502 drug pre-treatment did not reduce subsequent cell proliferation in vitro (Fig. 1), it significantly reduced subsequent bone tumor formation by 1833 (Fig. 5a- 
a
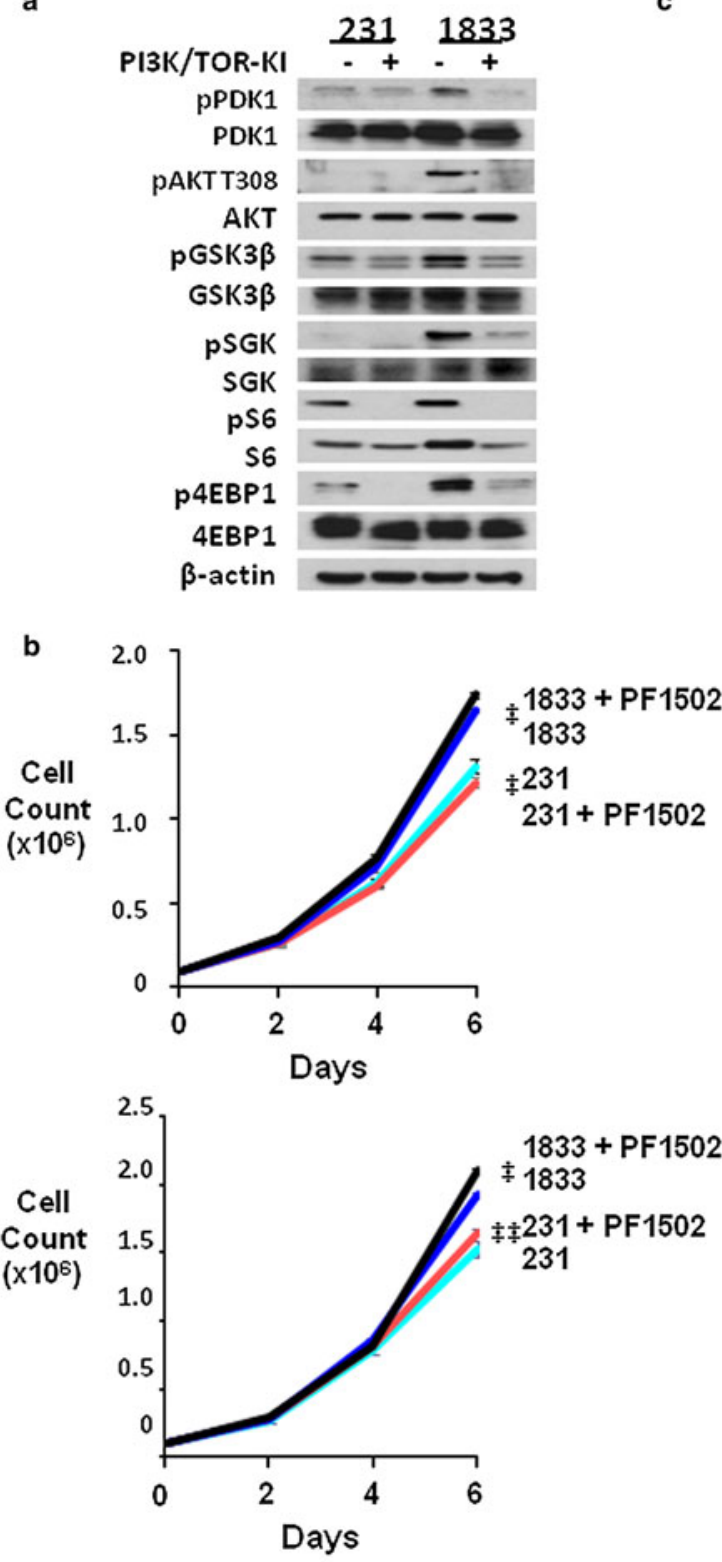

e

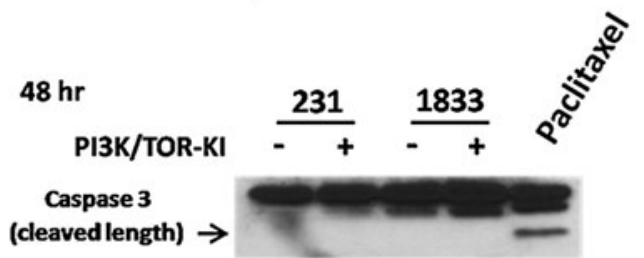

Fig. 1 PF1502 inhibits PI3K/mTOR activity in MDA-MB-231 and 1833 without affecting proliferation or caspase activation. a Cells were treated $48 \mathrm{~h}$ with $250 \mathrm{nM}$ PF1502 or DMSO control prior to Westerns of total and phospho-activated PI3K/mTOR effectors. b Cells were pre-treated with $250 \mathrm{nM}$ PF1502 for $48 \mathrm{~h}$ (top) or for 7 days (bottom) prior to seeding into cell culture without further drug and subsequent population growth is plotted as cell number over time. Mean cell number from triplicate repeats are plotted/time \pm SEM (comparative analysis of growth curves $T$ test ${ }^{\star} p=0.10,{ }^{*} p=0.20$ ).

c

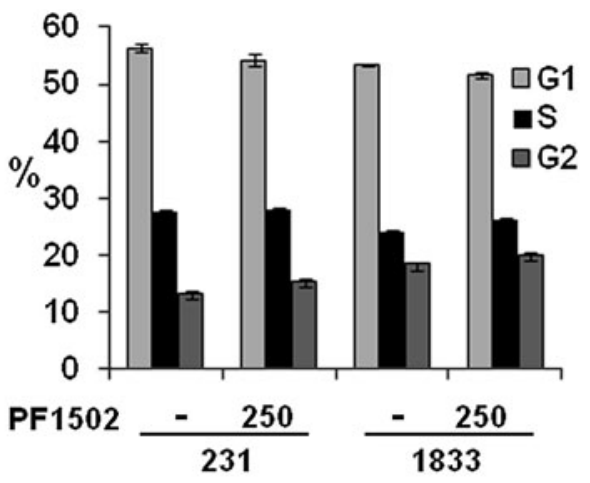

d
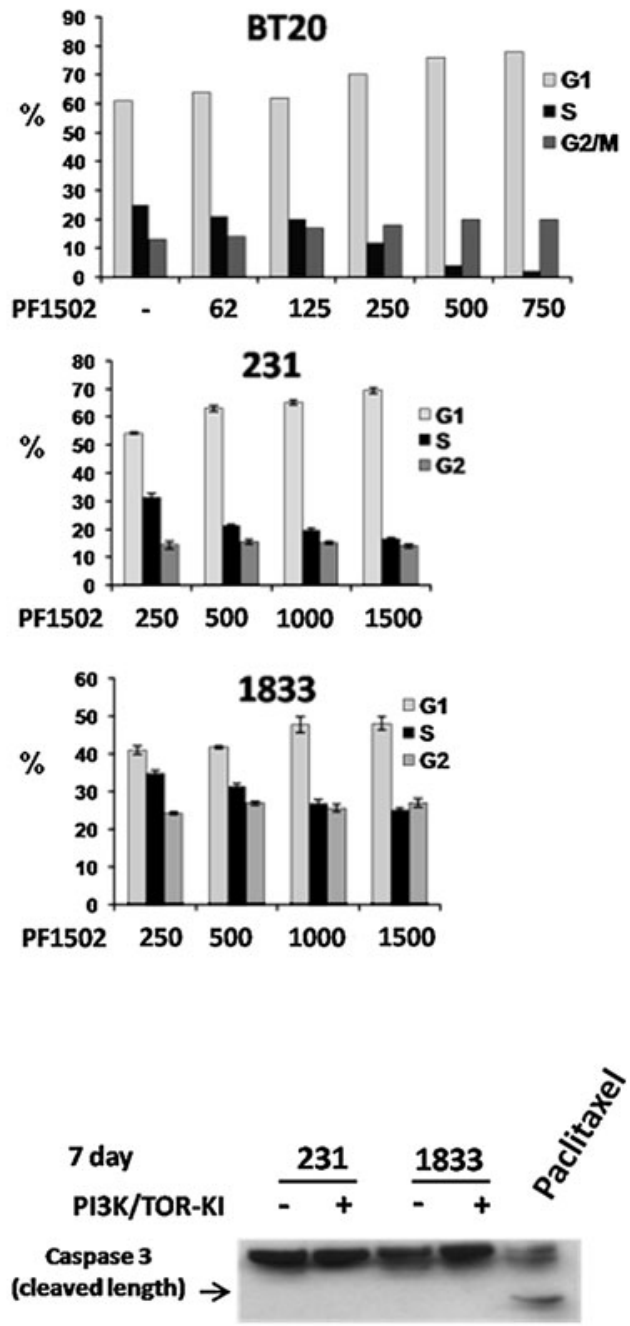

c Flow cytometry of 231 and 1833 cells treated with 250 nM PF1502 or vehicle control for $48 \mathrm{~h}$ (Cell cycle distribution after 7 days of therapy was also unchanged, not shown). Drug treatment did not yield any sub-G1 fraction. d Flow cytometry for BT20, MDA-MB-231 and 1833 cells treated with increasing nM PF1502 doses for $48 \mathrm{~h}$. Drug treatment did not yield any sub-G1 fraction. e Caspase 3 cleavage assay after $250 \mathrm{nM}$ PF1502 for $48 \mathrm{~h}$ (left) or 7 days (right). Positive control in far right lane shows MDA-MB-231 after $72 \mathrm{~h}$ of paclitaxel $100 \mathrm{nM}$ 

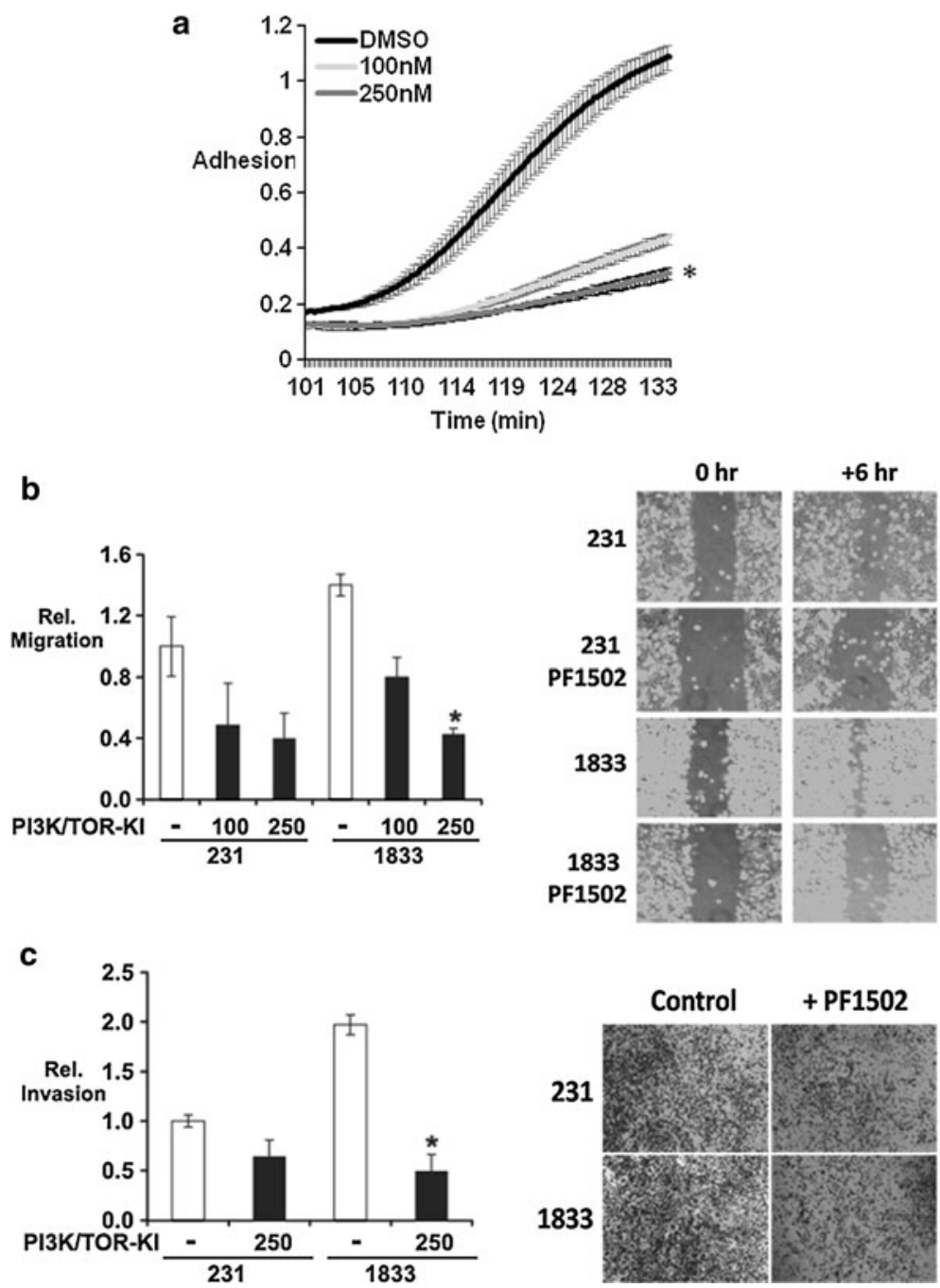

Fig. $2 \mathrm{PI} 3 \mathrm{~K} / \mathrm{mTOR}$ inhibition attenuates tumor cell adhesion, motility, and invasion. Cells were pre-treated with PF1502 at $250 \mathrm{nM}$, unless otherwise indicated, for 2 days prior to assays a Cell adhesion in 1833 cells \pm drug (mean \pm SEM, $T$ test for final time points vs

c). Notably, an appreciable reduction in tumor bioluminescence was evident as early as 3 days post-injection (Supplemental Fig S2), suggesting that PF1502 pre-treatment may modulate early steps in this metastatic model (extravasation and initial establishment of viable microcolonies). PF1502 pre-treatment did not significantly alter bone metastasis by parental 231 (Fig. 5a-c). The presence of metastatic tumor in bone was verified histopathologically at necropsy (Fig. 5d), but the decalcification required precluded tumor IHC assays for $\mathrm{p} 27$ and Ki67. Thus, at a dose that fails to affect cell survival or proliferation in vitro, PF1502 reduced the excess tumor cell motility, invasion, and metastasis of highly PI3K/mTOR-activated 1833 to levels seen with the parental 231 line.

It is noteworthy that while it significantly reduced bone metastasis, a one-week PF1502 pre-treatment prior to control, $p<0.002)$ b Relative migration $6 \mathrm{~h}$ after wounding of a confluent cell monolayer (graphed $\pm \mathrm{SEM}$, treated vs untreated $T$ test $* p=0.005$ ). c Mean transwell matrigel invasion \pm SEM ( $T$ test of treated vs control $* p=0.02$ )

injection into each of two mammary fat pads did not significantly decrease orthotopic growth of either 231 or 1833 tumors ( $\mathrm{n}=10$ tumors each), consistent with its lack of antiproliferative effect in cell culture (Fig. 5e). Of note, lymph nodal metastasis from primary orthotopic tumors appeared to be reduced by $\mathrm{PI} 3 \mathrm{~K} / \mathrm{mTOR}$ inhibition of injected cells: 4/5 animals injected with untreated cells developed metastases while only $2 / 5$ mice injected with drug pre-treated cells yielded tumors metastatic to nodes (see supplemental Fig S3, data not statistically significant).

Cytoplasmic p27 is linked to nodal metastasis and reduced survival in breast cancer patients

To further address the link between cytoplasmic p27 and metastasis, p27 localization was assessed by 
Fig. 3 PI3K/mTOR inhibition reduces cytoplasmic p27 and p27 knockdown phenocopies PF1502 treatment. Cells were treated $48 \mathrm{~h}$ with $250 \mathrm{nM}$ PF1502 or DMSO prior to Westerns of: a Total p27, p27pT157 and p27pT198 and b p27 in cytosolic $(C)$ and nuclear $(N)$ fractions. Cells were infected with shRNA p27 (+) or control (-) 5 days before the following assays. c Relative p27 levels with and without shRNAmediated knockdown. d Cell adhesion. e Mean relative migration $24 \mathrm{~h}$ after wounding of cell monolayer (mean \pm SEM $T$ test $* p=0.01$ for 1833 - vs + shp27).

f Relative transwell matrigel invasion over $24 \mathrm{~h}$ (mean \pm SEM $T$ test $* p<0.05$ for 1833 - vs + )
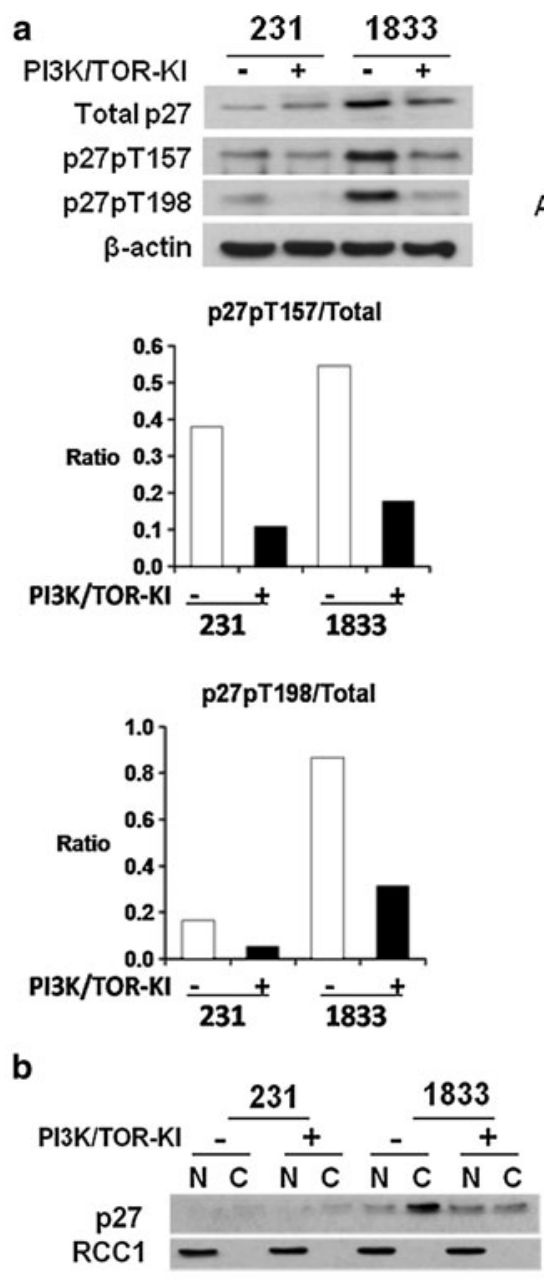

c

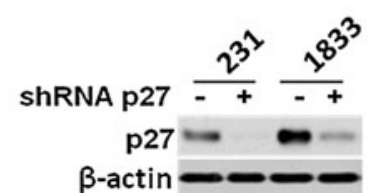

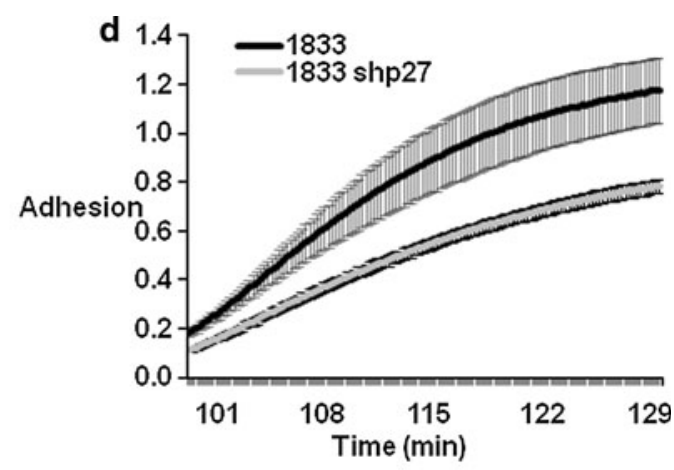

e

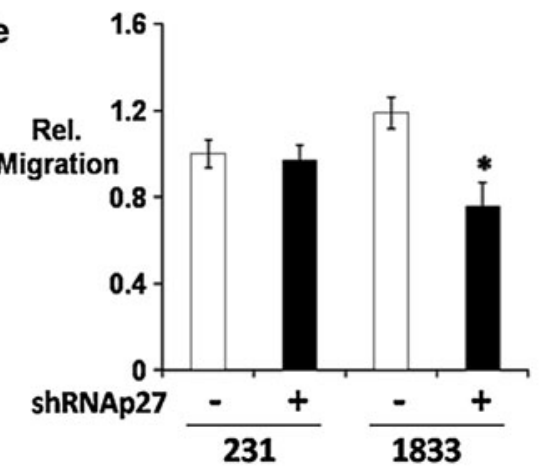

f

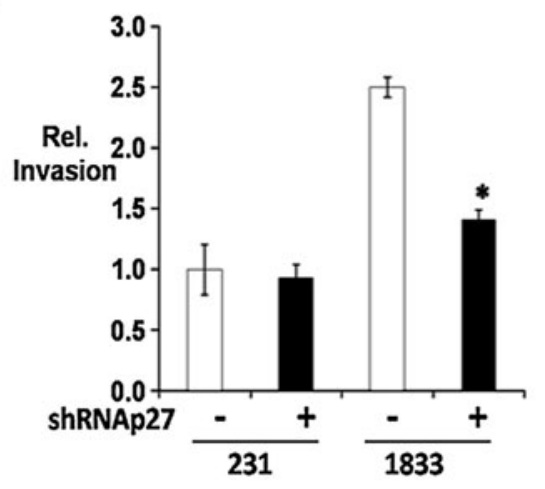

immunohistochemistry in 100 primary breast cancers with matched lymph nodal metastases (see Fig. 6a). Nuclear p27 staining was greater in primary tumors than in nodal metastases, with the mean \% tumor nuclei positive for $\mathrm{p} 27$ stain $57.5 \%$ in primary tumors and only $40 \%$ in nodal metastasis $(p<0.0004)$. Cytoplasmic p27 staining showed a trend toward increase between primary and nodal tumors. The proportion of tumor cells showing cytoplasmic p27 staining in the primary cancers was positively associated with the number of lymph nodes affected at diagnosis (Spearman's $r=0.22$, one-sided $p=0.007$ ), an early indicator of distant metastatic potential (Fig. 6b). Moreover, cytoplasmic p27 was associated with reduced disease-free (two-sided $p=0.04$, Log-rank test) and overall survival ( $p=0.05$ ) for these node positive cancers, when compared with cancers showing only nuclear p27 staining at diagnosis (Fig. 6c, d). These in vivo data further support the link between cytoplasmic p27 and metastatic tumor progression in human breast cancer patients.

\section{Discussion}

PI3K/mTOR signaling promotes tumor progression by activating cell proliferation, growth and survival [4] and has been implicated in tumor metastasis. Here we provide evidence that a novel catalytic PI3K/mTOR inhibitor may exert anti-tumor effects by opposing metastasis. Inhibition of effector kinases by the PI3K/mTOR inhibitor, PF1502, decreased C-terminal phosphorylation of p27, reduced its cytoplasmic localization, and attenuated tumor cell motility, invasion and metastasis. That these effects occur at a drug dose that failed to inhibit cell proliferation suggests that processes governing tumor metastasis downstream of PI3K/ 
Fig. 4 Expression of a phosphomimetic, cell-cycle inert p27 mutant conveys resistance to PF1502. a Western analysis shows GFP-p27CKT157DT198D (p27CK-DD) expression in 231 and 1833 (control represents emptyvector transfection).

b Migration in $231 \pm \mathrm{PF} 1502$

with or without p27CK-

T157DT198D, mean \pm SEM

( $T$ test of 231p27CK-DD [top] and 231 [bottom] with or without drug $* p=0.01$, ${ }^{\ddagger} p=0.11$; $231 \mathrm{CK}-\mathrm{DD}$ versus.

231 control $p<0.0001)$. c-d, Matrigel invasion of 231

(C) and 1833 cells

(D) transduced with p27CK-

$\mathrm{DD}$, with and without $48 \mathrm{~h}$ PF1502 $250 \mathrm{nM}$ and graphed \pm SEM. (T-tests as indicated: $* p=0.003$,

${ }^{*} p=0.068$ (left); $* p=0.0002$,

${ }^{*} p=0.064$ (right)). (c,d)

Representative

photomicrographs demonstrate differential cell invasion with and without p27CK-DD expression in 231 and 1833 a

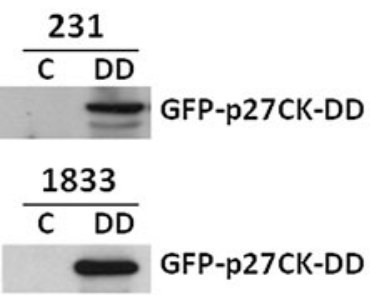

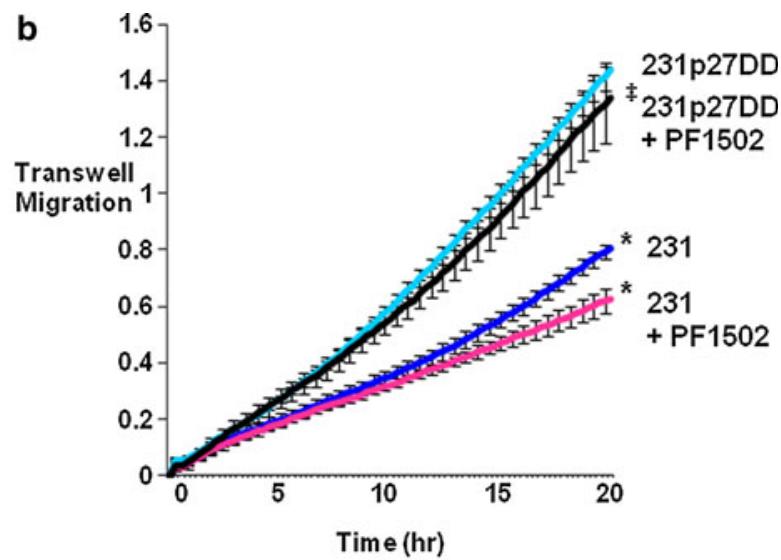

c
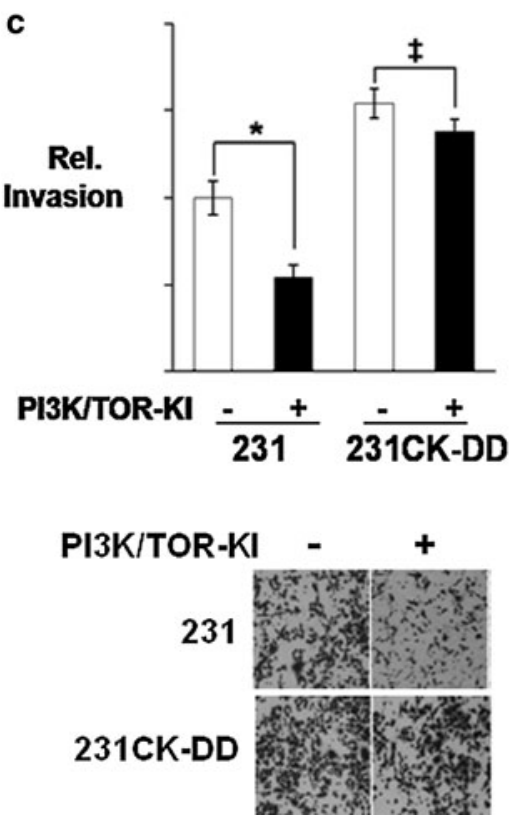

d
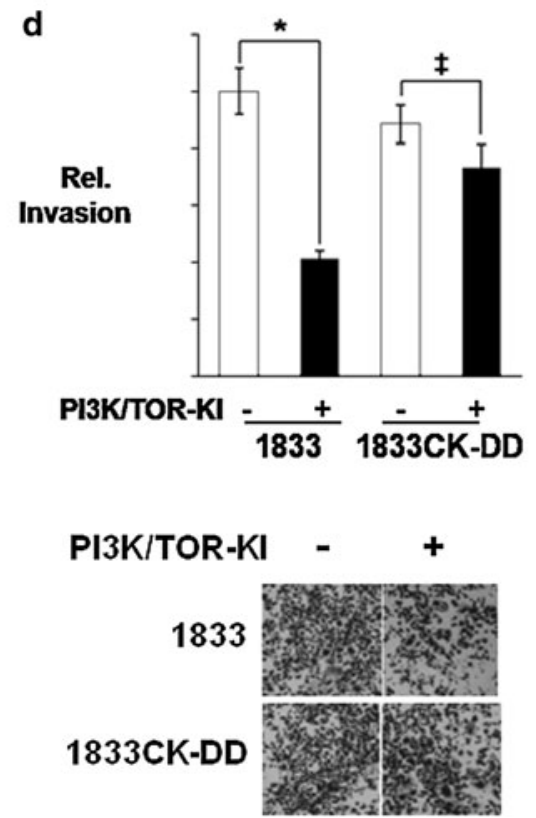

mTOR may be independent of those driving proliferation. Thus, PI3K/mTOR inhibition, in lines that appear resistant to the compound's antiproliferative action and indeed at a dose that fails to prevent primary tumor growth, may have potential to prevent or attenuate the establishment of micrometastatic foci that initiate systemic tumor spread.

While there is evidence that both PI3K and mTOR pathways may contribute to metastasis, the mechanisms mediating this are not well understood. In human breast cancers, pAKT and p4EBP1 were greater in matched distant metastases compared to primary tumors [26]. mTORC2-dependent AKT activation increased ovarian cancer motility in vitro and metastasis in vivo [8], and PI3K inhibition prevented metastasis in a murine thyroid cancer model [27]. mTORC1 increased migration in gastric cancer cells [28], mTORC2 drove migration and invasion in a glioma model [29] and both Rictor and Raptor expression are required for metastasis of a colorectal cancer xenograft [30]. While none of these reports distinguished between effects on tumor growth versus direct effects on metastasis, they raise the possibility that PI3K/mTOR inhibition may not only impair biosynthetic processes driving tumor growth, but also modulate the metastatic process.

The CDK inhibitor p27 plays dual roles to regulate both cell proliferation and motility. While p27 restrains normal cell proliferation through cyclin-Cdk2 inhibition [9], it can also modulate cell motility through mechanisms involving its C-terminal domain [31, 32]. p27 can bind RhoA to inactivate RhoA/ROCK and drive cell motility [16]. Motility effects of p27 may exist in normal cells, since p27-dependent migration is essential for normal cortical neuron development in vivo in murine embryos [33, 34]. In cancers, oncogenic PI3K/mTOR activation increases p27 phosphorylation at T157 and/or T198 and promotes cytoplasmic p27 mislocalization [10-14]. Indeed, PI3K-mediated p27 phosphorylation at T198 enhances its binding to and inhibition of RhoA [14].

The balance between growth inhibitory and acquired pro-motility/metastatic functions may determine effects of 

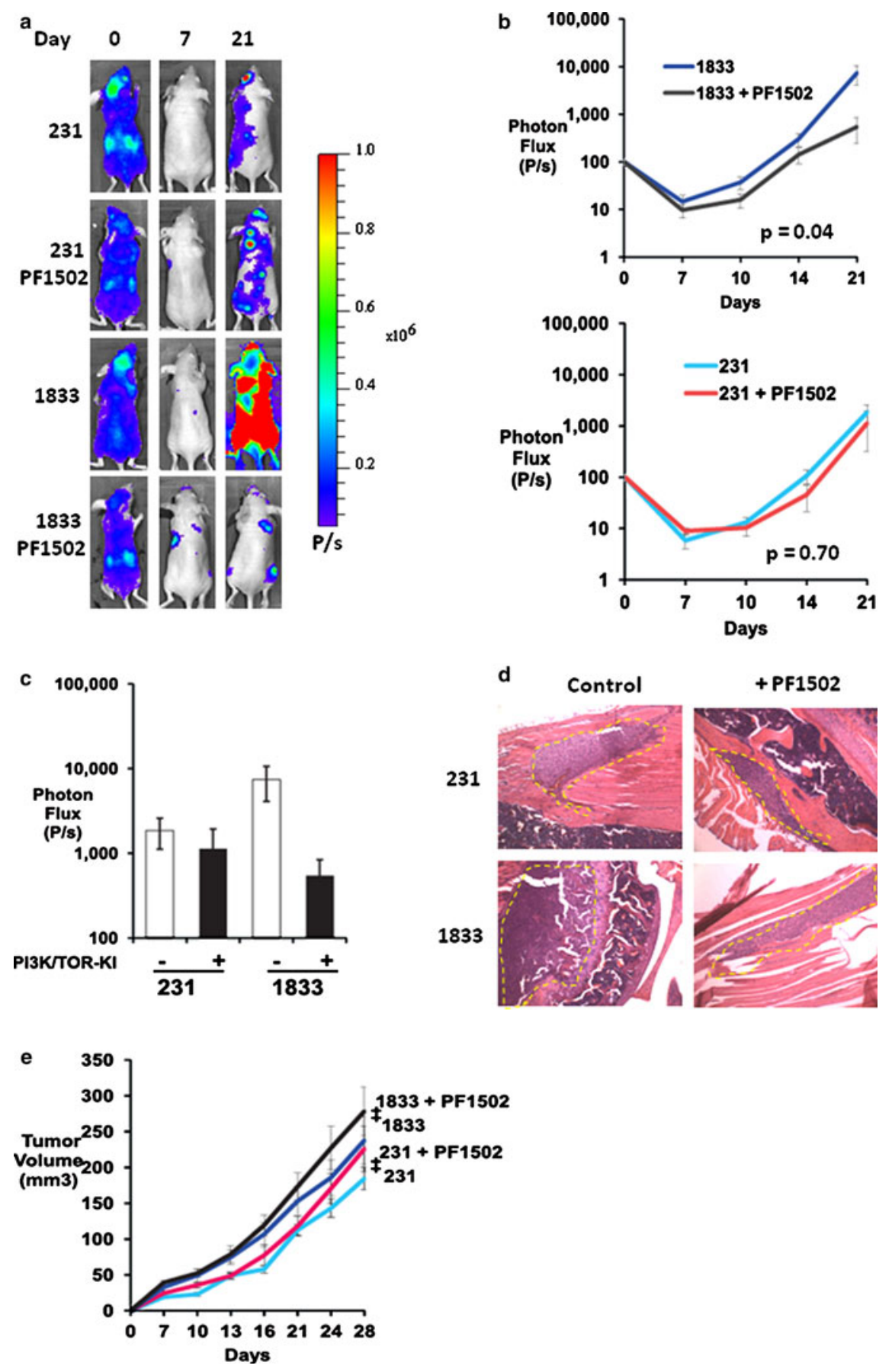

Fig. 5 PI3K/mTOR inhibition abrogates bone metastatic outgrowth in vivo. 231 and 1833 were cultured $\pm 250 \mathrm{nM}$ PF1502 for 7 days prior to intracardiac injection. No further drug was given thereafter. a Representative bioluminescence at 0,7 and 21 days post-injection. b Mean normalized photon flux (P/s, log scale) for 1833 (top) and 231 (bottom) \pm SEM versus time (comparative analysis of growth curves, ${ }^{*} p$ values as indicated). c, Mean normalized photon flux $(\mathrm{P} / \mathrm{s})$ for

p27 in different cancers. For example, p27 knockdown increased proliferation and enhanced primary tumor formation in a Ras-driven mouse tumor model, but impaired tumor invasion [35]. In many cancers, p27 protein levels are
1833 and 231 at day $21 \pm$ SEM. d, Representative bone metastasis histopathology (tumor outlined in yellow). e Growth curves of orthotopic tumors arising from 231 and 1833 cultured in vitro \pm $250 \mathrm{nM}$ PF1502 for 7 days prior to mammary fat pad injection $\left({ }^{*} p>0.50\right)$. Animals received no drug therapy. See also supplemental Fig S2 showing nodal metastasis from orthotopic primary tumors arising from drug-pretreated cells or controls

reduced due to miRNA-mediated loss of synthesis or accelerated proteolysis [9]. In contrast, tumors with activated AKT exhibit abundant cytoplasmic p27 [9]. Cytoplasmic p27 was implicated in local invasion in an AKT-driven 
human glioma xenograft [36] and overexpression of cytoplasmic $\mathrm{p} 27^{\mathrm{CK}-}$ enhanced murine melanoma metastasis [37].

Here we investigated further the link between $\mathrm{PI} 3 \mathrm{~K} /$ mTOR activation, p27 and cancer metastasis. The wellcharacterized highly bone-metastatic 1833 model showed activation of PI3K and mTOR effector kinases and a p27dependent increase in cell motility and invasion in vitro. The dual PI3K/mTOR inhibitor drug, PF1502, inhibited PI3K as evidenced by decreased pPDK1, and effectively impaired activation of both TORC 1 and TORC 2 substrates. It also reduced C-terminal p27 phosphorylation, cytoplasmic p27 accumulation, and phenocopied effects of p27 knockdown to impair cell adhesion, motility, and invasion in vitro. The p27CK-DD mutant, a T157/T198 phosphomimetic, increased motility and invasion of parental 231 cells. It also promoted resistance to in vitro effects of PI3K/ mTOR inhibition on invasion and motility in both 231 and 1833 cells. That the phosphomimetic p27 did not fully reverse PF1502 effects on motility/invasion may reflect that aspartate at T157/T198 fails to fully mimic phosphorylation, or that p27-independent mediators also contribute to $\mathrm{PI} 3 \mathrm{~K} / \mathrm{mTOR}$ driven tumor metastasis.

The present in vivo experimental approach was not intended to mimic patient therapy, but rather to assay the requirement for $\mathrm{PI} 3 \mathrm{~K} / \mathrm{mTOR}$ pathway activity at the time of injection for subsequent primary and metastatic tumor outgrowth. Notably, prior PI3K/mTOR inhibition by PF1502 that failed to restrain cell proliferation during or after one week in culture in vitro, and did not reduce primary orthotopic tumor growth, significantly impaired the subsequent outgrowth of bone metastatic tumors after intracardiac injection in vivo. In addition, nodal metastasis from orthotopic primary tumors also showed a trend toward reduction with drug pre-treatment prior to injection. Thus, drug effects to impair metastasis in this model appear to occur despite the lack of an antiproliferative effect, and may modulate tumor cell extravasation and establishment of metastatic foci, as suggested by early IVIS data in the first few days post-injection. Present data extend prior work implicating PI3K and mTOR pathways in tumor growth and metastasis [30, 38], and suggest that drug effects on cell proliferation or growth may be separable from those driving metastasis. Indeed, malignant progression of cells resistant to antiproliferative effects of a novel PI3K/mTOR kinase inhibitor may still be interdicted at the level of metastasis - an effect that might be missed by traditional phase 1 clinical trials focused on tumor size reduction.

A relationship between cytoplasmic p 27 and metastasis is supported by the novel observation that there is a positive correlation between the $\%$ of primary breast cancer cells a

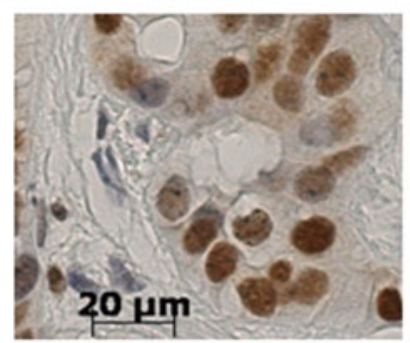

Nuclear + Cytoplasmic

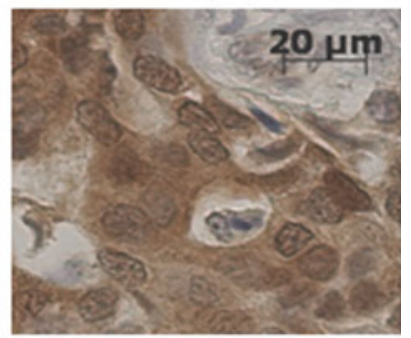

b

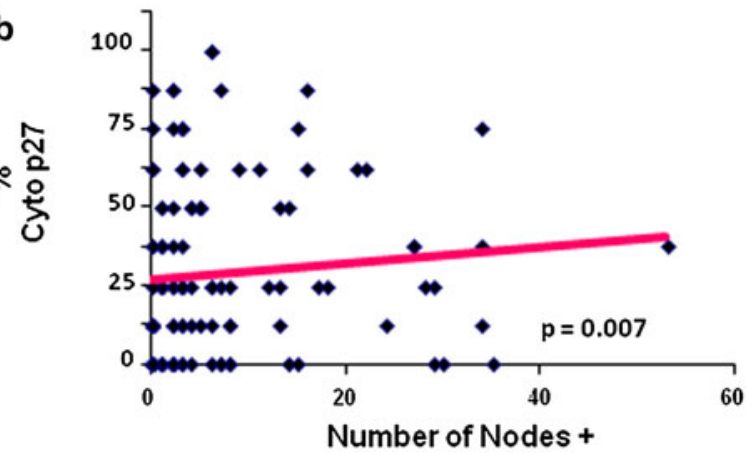

C
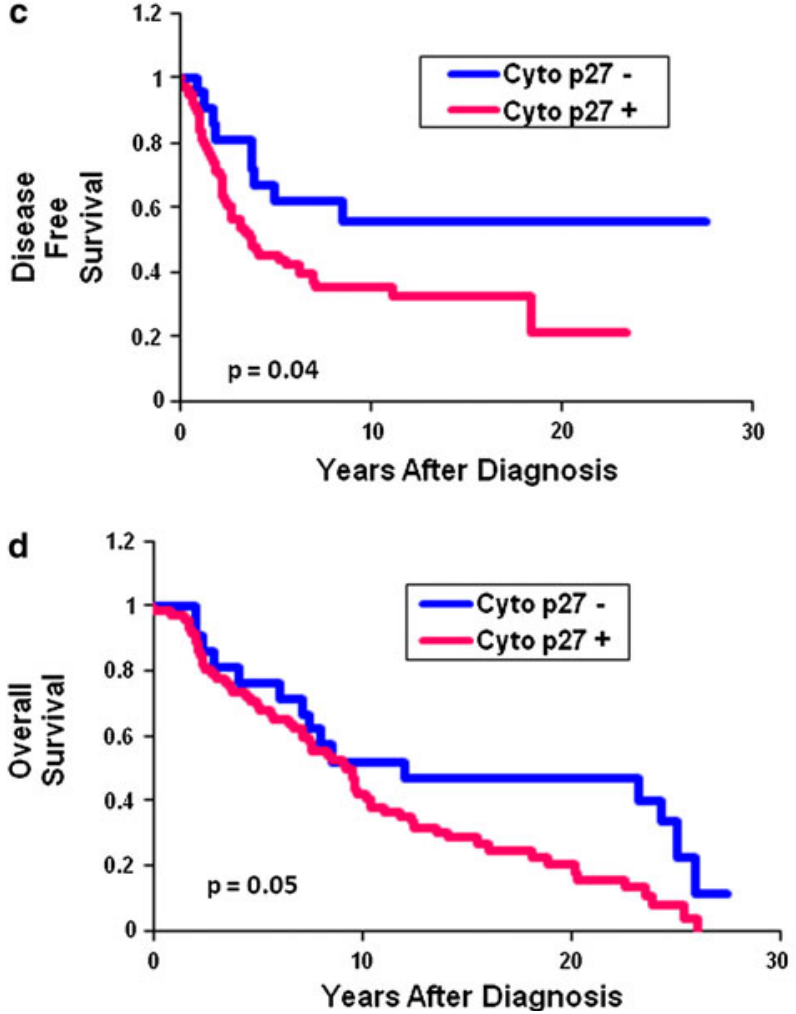

Fig. 6 Cytoplasmic p27 correlates with lymph node invasion at diagnosis and breast cancer outcome. a IHC demonstrating predominantly nuclear (left) or strong nuclear + cytoplasmic p27 staining (right). b Primary tumor cytoplasmic p27 as it relates to number of nodes positive at diagnosis. c Kaplan-Meier analysis of nuclear only versus cytoplasmic positive tumors $(N=21$ and $N=73$, respectively) and disease-free survival. d Kaplan-Meier analysis of nuclear only versus cytoplasmic positive tumors and overall survival 
showing cytoplasmic p27 staining with the number of nodes affected at diagnosis. While loss of nuclear p27 is strongly associated with poor patient outcome [9], few studies have addressed the prognostic import of cytoplasmic p27, which is observed in up to $60 \%$ of human cancers. Cytoplasmic p27 is correlated with poor outcome in colon and prostate cancers and lymphoma [9]. p27 localization to cytoplasm in primary breast cancers was associated with AKT activation[10-12]. The present study supports our earlier report associating cytoplasmic p27 in primary breast cancer with a reduced metastasis free interval [10], and provides the first association with reduced patient survival.

PI3K and/or mTOR inhibitors have shown significant therapeutic promise in a several cancers [3]. Dual PI3K/ mTOR catalytic-site inhibitors have begun to enter clinical trials [3] and have shown improved anti-tumor effects over allosteric mTORC1 inhibitors in pre-clinical models of breast [19-21], pancreatic [22], and renal cell cancers [39], melanoma [40], glioma [21,41], multiple myeloma [42], and acute myeloid leukemia [43]. The present work suggests the antiproliferative effects of $\mathrm{PI} 3 \mathrm{~K} / \mathrm{mTOR}$ inhibitor drugs may be distinct from their anti-metastatic action. The latter may result in part from their effects to abrogate cytoplasmic p27 accumulation. This work has implications for the clinical application of this new class of dual catalytic-site PI3K/mTOR inhibitors: in addition to their effects to check primary tumor growth, PI3K/mTOR inhibitors may also help prevent establishment of metastasis by clinically occult tumor cells, proving a rationale for trials investigating their potential to prevent systemic metastases early in the disease course. Furthermore, the presence of cytoplasmic p27 may identify tumors with $\mathrm{PI} 3 \mathrm{~K} / \mathrm{mTOR}$ activation and provide a potential biomarker of PI3K/mTOR inhibitor therapeutic efficacy.

\section{Methods}

Cell culture and drug treatment

Luciferase tagged MDA-MB-231 and MDA-MB-1833 were grown as in [44]. PF-04691502 was dissolved in DMSO, stored at $-80{ }^{\circ} \mathrm{C}$ at $10 \mathrm{mM}$ and used at $100-250 \mathrm{nM}$ in culture media. For prolonged treatment, drug was renewed every $48 \mathrm{~h}$ in culture.

Antibodies and western blots

Westerns were as described [14]. Antibodies to p4EBP1, 4EBP1, pAKT, AKT, Caspase 3, pGSK3 $\beta$, pPDK1, PDK1, pRSK, pS6, S6, p27, GSK3 $\beta$, RSK, pSGK, GFP and SGK from Cell Signaling; RCC1 from Transduction labs and to p27pT157 and p27pT198 from R\&D.
Wound-healing and transwell migration assays

A linear scratch/wound was made on confluent cell monolayers and wound healing assayed as described [14]. Relative migration was calculated by setting MDA-MB231 parental cell migration arbitrarily at 1 and adjusting all other groups to that value.

Matrigel invasion assays

Transwell invasion assayed as in [14]. Relative invasion was calculated setting invasion of control group to 1 and comparing all other groups to that value.

Automated transwell and adhesion assays

Automated transwell and adhesion assays used the RealTime Cell Analysis system from Xcelligence. For adhesion assays 20,000 cells were plated onto "E plates" from Xcelligence and adhesion measured over $2 \mathrm{~h}$. For transwell migration assays, 20,000 cells were seeded onto a semipermeable membrane without matrigel in the upper chamber in serum-free medium, with $10 \%$ FBS added in the bottom chamber. A two-sided $t$ test was used to compare the endpoint for each group in each experiment.

Lentiviral expression of p27 phosphomimetic mutants

Phosphomimetic p27 mutations converting T157 and T197 to aspartic acid were introduced into EGFP-p27CK- (S. Dowdy, UCSD) by site-directed mutagenesis and transfected into 231 and 1833, selected with G418 and pooled. Lenteviral vectors bearing p27CK-T157DT198D phosphomimetic mutations were generated and transduced into MDA-MB-231, and 1833.

\section{Flow cytometry}

Cell cycle distribution was assayed by Bromodeoxyuridine (BrdU) pulse labelling and flow cytometry as described [14].

Intracellular localization of p27

Nuclear cytoplasmic fractionation was as described [10]. Nuclear RCC1 served as fractionation control. Cytoplasmic proteins showed no leak into the nuclear fraction with this methodology [10].

Lentiviral shRNA production and infection

Lentivirus vector encoding p27 shRNA (Open Biosystems) was co-transfected with Delta VPR and CMV VSVG 
plasmids (Addgene) into asynchronous HEK-293T with Lipofectamine Plus (Roche). Viral supernatants were collected at $48 \mathrm{~h}$. Cells were infected twice in the presence of $6 \mu \mathrm{g} / \mathrm{ml}$ protamine sulphate. At 3-5 days post infection, high uniform GFP positivity was verified and p27 assayed by blotting.

\section{Animal studies}

Animal work was approved by the Institutional Animal Care and Use Committee. For bone metastasis assays, at least ten animals in each arm were injected with $10^{5}$ viable cells in $0.1 \mathrm{ml}$ PBS were injected into the left ventricle of 5 week old female Balb/c nude mice (Charles River) \pm prior treatment in culture with $250 \mathrm{nM}$ PF1502 or vehicle control over the preceeding 7 days. Mice were injected intraperitoneally with $1.5 \mathrm{mg}$ of d-luciferin $\left(15 \mathrm{mg} \mathrm{ml}^{-1}\right.$ in PBS) and imaged by Xenogen IVIS system on day 0 and weekly thereafter as in [23]. Bioluminescence (BLI) plots of photon flux were calculated for each mouse. Values were normalized to that obtained immediately after xenografting (day 0) such that all mice had a starting BLI signal of 100. Animals were weighed twice-weekly. Leg and spinal tissues were recovered at necropsy at 3 weeks for hemotoxylin and eosin ( $\mathrm{H} \& \mathrm{E})$ staining histopathology unless morbidity required earlier euthanization. The decalcification methods required for histopathologic analysis of bone metastasis precluded IHC for p27, Ki67 and pS6 on xenograft tumors.

Similarly 231 and 1833 were treated \pm 250 nM PF1502 for $7 \mathrm{~d}$ prior to orthotopic injection of $10^{6}$ cells in $100 \mu \mathrm{l}$ matrigel into each of two mammary fat pads, with $n=5$ animals (10 tumors) per group. Weekly IVIS followed development of nodal metastasis from primary tumors.

\section{Statistical analysis of growth/proliferation curves}

The statistical differences between growth curves were calculated using 'compareGrowthCurves' function of the statmod software package at the following website (http:// bioinf.wehi.edu.au/software/compareCurves). This analysis was applied for cellular proliferation assays, orthotopic tumor growth curves, and IVIS metastatic tumor growth curves.

Immunohistochemistry and analysis of human tumor samples

One hundred primary human breast cancers and matched nodal metastasis, and thirty primary node negative breast cancers were obtained from the de-identified tumor bank and database of UMSCCC Tissue Core Facility. p27 was evaluated by immunohistochemistry as in [45]. The $\%$ cells showing nuclear and/or cytoplasmic p27 staining was scored independently by two pathologists (C. Milikowski and T. Ince). Means (range) for the node positive group were as follows: age $52 \mathrm{yrs}(27-72)$, tumor size $4.3 \mathrm{~cm}$ (1.2-18); \# positive nodes 9 (1-53), follow-up $10 \mathrm{yrs}$ (0.8-27.5). $59 \%$ were ER + , $88 \%$ grade 2 or 3, with distant relapse in $62 \%$. p27 correlation with node positivity was scored using the Spearman analysis with node number as a continuous variable. Kaplan-Meier curves were generated for node-positive patients after excluding primary tumors that showed no p27 staining $(n=3)$. Statistical significance was assessed by log rank test.

Acknowledgments We acknowledge support of lab members, the UMSCCC Tissue Bank, Oncogenomics and Analytical Imaging Core Facilities, and grant funding from the Doris Duke Charitable Foundation and NCI2R01CA105118-05A. We thank Julie Kan, PhD and Pfizer for providing PF-04691502 compound for these studies.

Conflict of interest The authors declare that they have no conflicts of interest.

Open Access This article is distributed under the terms of the Creative Commons Attribution Noncommercial License which permits any noncommercial use, distribution, and reproduction in any medium, provided the original author(s) and the source are credited.

\section{References}

1. Mundy GR (2002) Metastasis to bone: causes, consequences and therapeutic opportunities. Nat Rev Cancer 2(8):584-593

2. Manning BD, Cantley LC (2007) AKT/PKB signaling: navigating downstream. Cell 129(7):1261-1274

3. Wander SA, Hennessy BT, Slingerland JM (2011) Next generation mTOR inhibitors in clinical oncology: how pathway complexity informs therapeutic strategy. J Clin Invest 121(4):1231-1241

4. Sabatini DM (2006) mTOR and cancer: insights into a complex relationship. Nat Rev Cancer 6(9):729-734

5. Ridley AJ, Schwartz MA, Burridge K, Firtel RA, Ginsberg MH, Borisy G, Parsons JT, Horwitz AR (2003) Cell migration: integrating signals from front to back. Science 302(5651):1704-1709

6. Klos KS, Wyszomierski SL, Sun M, Tan M, Zhou X, Li P, Yang W, Yin G, Hittelman WN, Yu D (2006) ErbB2 increases vascular endothelial growth factor protein synthesis via activation of mammalian target of rapamycin/p70S6K leading to increased angiogenesis and spontaneous metastasis of human breast cancer cells. Cancer Res 66(4):2028-2037

7. Zhang F, Zhang X, Li M, Chen P, Zhang B, Guo H, Cao W, Wei X, Cao X, Hao X, Zhang N (2010) mTOR complex component Rictor interacts with PKCzeta and regulates cancer cell metastasis. Cancer Res 70(22):9360-9370

8. Kim EK, Yun SJ, Ha JM, Kim YW, Jin IH, Yun J, Shin HK, Song SH, Kim JH, Lee JS, Kim CD, Bae SS (2011) Selective activation of Akt1 by mammalian target of rapamycin complex 2 regulates cancer cell migration, invasion, and metastasis. Oncogene 30(26): 2954-63

9. Chu IM, Hengst L, Slingerland JM (2008) The Cdk inhibitor p27 in human cancer: prognostic potential and relevance to anticancer therapy. Nat Rev Cancer 8(4):253-267 
10. Liang J, Zubovitz J, Petrocelli T, Kotchetkov R, Connor MK, Han K, Lee JH, Ciarallo S, Catzavelos C, Beniston R, Franssen E, Slingerland JM (2002) PKB/Akt phosphorylates p27, impairs nuclear import of p27 and opposes p27-mediated G1 arrest. Nat Med 8(10):1153-1160

11. Viglietto G, Motti ML, Bruni P, Melillo RM, D'Alessio A, Califano D, Vinci F, Chiappetta G, Tsichlis P, Bellacosa A, Fusco A, Santoro M (2002) Cytoplasmic relocalization and inhibition of the cyclin-dependent kinase inhibitor p27(Kip1) by PKB/Aktmediated phosphorylation in breast cancer. Nat Med 8(10): 1136-1144

12. Shin I, Yakes FM, Rojo F, Shin NY, Bakin AV, Baselga J, Arteaga CL (2002) PKB/Akt mediates cell-cycle progression by phosphorylation of p27(Kip1) at threonine 157 and modulation of its cellular localization. Nat Med 8(10):1145-1152

13. Hong F, Larrea MD, Doughty C, Kwiatkowski DJ, Squillace R, Slingerland JM (2008) mTOR-raptor binds and activates SGK1 to regulate p27 phosphorylation. Mol Cell 30(6):701-711

14. Larrea MD, Hong F, Wander SA, da Silva TG, Helfman D, Lannigan D, Smith JA, Slingerland JM (2009) RSK1 drives p27Kip1 phosphorylation at T198 to promote RhoA inhibition and increase cell motility. Proc Natl Acad Sci USA 106(23): 9268-9273

15. Fujita N, Sato S, Tsuruo T (2003) Phosphorylation of p27Kip1 at threonine 198 by p90 ribosomal protein S6 kinases promotes its binding to 14-3-3 and cytoplasmic localization. J Biol Chem 278(49):49254-49260

16. Besson A, Gurian-West M, Schmidt A, Hall A, Roberts JM (2004) p27Kip1 modulates cell migration through the regulation of RhoA activation. Genes Dev 18(8):862-876

17. Besson A, Hwang HC, Cicero S, Donovan SL, Gurian-West M, Johnson D, Clurman BE, Dyer MA, Roberts JM (2007) Discovery of an oncogenic activity in p27Kip1 that causes stem cell expansion and a multiple tumor phenotype. Genes Dev 21(14): 1731-1746

18. Meric-Bernstam F, Gonzalez-Angulo AM (2009) Targeting the mTOR signaling network for cancer therapy. J Clin Oncol 27(13):2278-2287

19. Serra V, Markman B, Scaltriti M, Eichhorn PJ, Valero V, Guzman M, Botero ML, Llonch E, Atzori F, Di CS, Maira M, GarciaEcheverria C, Parra JL, Arribas J, Baselga J (2008) NVPBEZ235, a dual PI3K/mTOR inhibitor, prevents PI3K signaling and inhibits the growth of cancer cells with activating PI3K mutations. Cancer Res 68(19):8022-8030

20. Brachmann SM, Hofmann I, Schnell C, Fritsch C, Wee S, Lane H, Wang S, Garcia-Echeverria C, Maira SM (2009) Specific apoptosis induction by the dual PI3K/mTor inhibitor NVPBEZ235 in HER2 amplified and PIK3CA mutant breast cancer cells. Proc Natl Acad Sci U S A 106(52):22299-22304

21. Mallon R, Hollander I, Feldberg L, Lucas J, Soloveva V, Venkatesan A, Dehnhardt C, Delos SE, Chen Z, Dos SO, AyralKaloustian S, Gibbons J (2010) Antitumor efficacy profile of PKI-402, a dual phosphatidylinositol 3-kinase/mammalian target of rapamycin inhibitor. Mol Cancer Ther 9(4):976-984

22. Cao P, Maira SM, Garcia-Echeverria C, Hedley DW (2009) Activity of a novel, dual PI3-kinase/mTor inhibitor NVP-BEZ235 against primary human pancreatic cancers grown as orthotopic xenografts. Br J Cancer 100(8):1267-1276

23. Kang Y, Siegel PM, Shu W, Drobnjak M, Kakonen SM, CordonCardo C, Guise TA, Massague J (2003) A multigenic program mediating breast cancer metastasis to bone. Cancer Cell 3(6): 537-549

24. Yuan J, Mehta PP, Yin MJ, Sun S, Zou A, Chen J, Rafidi K, Feng Z, Nickel J, Engebretsen J, Hallin J, Blasina A, Zhang E, Nguyen L, Sun M, Vogt PK, McHarg A, Cheng H, Christensen JG, Kan JL, Bagrodia S (2011) PF-04691502, a potent and selective oral inhibitor of PI3K and mTOR kinases with antitumor activity. Mol Cancer Ther 10(11) 2189-99

25. Wander SA, Zhao D, Slingerland JM (2011) p27: a barometer of signaling deregulation and potential predictor of response to targeted therapies. Clin Cancer Res 17(1):12-18

26. Akcakanat A, Sahin A, Shaye AN, Velasco MA, Meric-Bernstam F (2008) Comparison of Akt/mTOR signaling in primary breast tumors and matched distant metastases. Cancer 112(11):23522358

27. Furuya F, Lu C, Willingham MC, Cheng SY (2007) Inhibition of phosphatidylinositol 3-kinase delays tumor progression and blocks metastatic spread in a mouse model of thyroid cancer. Carcinogenesis 28(12):2451-2458

28. Hashimoto I, Koizumi K, Tatematsu M, Minami T, Cho S, Takeno N, Nakashima A, Sakurai H, Saito S, Tsukada K, Saiki I (2008) Blocking on the CXCR4/mTOR signalling pathway induces the anti-metastatic properties and autophagic cell death in peritoneal disseminated gastric cancer cells. Eur J Cancer 44(7): 1022-1029

29. Masri J, Bernath A, Martin J, Jo OD, Vartanian R, Funk A, Gera J (2007) mTORC2 activity is elevated in gliomas and promotes growth and cell motility via overexpression of rictor. Cancer Res 67(24):11712-11720

30. Gulhati P, Bowen KA, Liu J, Stevens PD, Rychahou PG, Chen M, Lee EY, Weiss HL, O'Connor KL, Gao T, Evers BM (2011) mTORC1 and mTORC2 regulate EMT, motility, and metastasis of colorectal cancer via RhoA and Rac1 signaling pathways. Cancer Res 71(9):3246-3256

31. McAllister SS, Becker-Hapak M, Pintucci G, Pagano M, Dowdy SF (2003) Novel p27(kip1) C-terminal scatter domain mediates Rac-dependent cell migration independent of cell cycle arrest functions. Mol Cell Biol 23(1):216-228

32. Nagahara H, Vocero-Akbani AM, Synder EL, Ho A, Latham DG, Lissy NA, Becker-Hapak M, Ezhevsky SA, Dowdy SF (1998) Transduction of full-length TAT fusion proteins into mammalian cells: TAT-p27Kip1 induces cell migration. Nat Med 4(12): 1449-1452

33. Kawauchi T, Chihama K, Nabeshima Y, Hoshino M (2006) Cdk5 phosphorylates and stabilizes p27kip1 contributing to actin organization and cortical neuronal migration. Nat Cell Biol 8(1): $17-26$

34. Nguyen L, Besson A, Heng JI, Schuurmans C, Teboul L, Parras C, Philpott A, Roberts JM, Guillemot F (2006) p27kip1 independently promotes neuronal differentiation and migration in the cerebral cortex. Genes Dev 20(11):1511-1524

35. Kelly-Spratt KS, Philipp-Staheli J, Gurley KE, Hoon-Kim K, Knoblaugh S, Kemp CJ (2009) Inhibition of PI-3 K restores nuclear p27Kip1 expression in a mouse model of Kras-driven lung cancer. Oncogene 28(41):3652-3662

36. Wu FY, Wang SE, Sanders ME, Shin I, Rojo F, Baselga J, Arteaga CL (2006) Reduction of cytosolic p27(Kip1) inhibits cancer cell motility, survival, and tumorigenicity. Cancer Res 66(4):2162-2172

37. Denicourt C, Saenz CC, Datnow B, Cui XS, Dowdy SF (2007) Relocalized p27(KiP1) tumor suppressor functions as a cytoplasmic metastatic oncogene in melanoma. Cancer Res 67(19): 9238-9243

38. Thiery JP, Acloque H, Huang RY, Nieto MA (2009) Epithelialmesenchymal transitions in development and disease. Cell 139(5):871-890

39. Cho DC, Cohen MB, Panka DJ, Collins M, Ghebremichael M, Atkins MB, Signoretti S, Mier JW (2010) The efficacy of the novel dual PI3-kinase/mTOR inhibitor NVP-BEZ235 compared with rapamycin in renal cell carcinoma. Clin Cancer Res 16(14): $3628-3638$

40. Marone R, Erhart D, Mertz AC, Bohnacker T, Schnell C, Cmiljanovic V, Stauffer F, Garcia-Echeverria C, Giese B, Maira 
SM, Wymann MP (2009) Targeting melanoma with dual phosphoinositide 3-kinase/mammalian target of rapamycin inhibitors. Mol Cancer Res 7(4):601-613

41. Liu TJ, Koul D, LaFortune T, Tiao N, Shen RJ, Maira SM, Garcia-Echevrria C, Yung WK (2009) NVP-BEZ235, a novel dual phosphatidylinositol 3-kinase/mammalian target of rapamycin inhibitor, elicits multifaceted antitumor activities in human gliomas. Mol Cancer Ther 8(8):2204-2210

42. McMillin DW, Ooi M, Delmore J, Negri J, Hayden P, Mitsiades N, Jakubikova J, Maira SM, Garcia-Echeverria C, Schlossman R, Munshi NC, Richardson PG, Anderson KC, Mitsiades CS (2009) Antimyeloma activity of the orally bioavailable dual phosphatidylinositol 3-kinase/mammalian target of rapamycin inhibitor NVP-BEZ235. Cancer Res 69(14):5835-5842
43. Park S, Chapuis N, Bardet V, Tamburini J, Gallay N, Willems L, Knight ZA, Shokat KM, Azar N, Viguie F, Ifrah N, Dreyfus F, Mayeux P, Lacombe C, Bouscary D (2008) PI-103, a dual inhibitor of Class IA phosphatidylinositide 3-kinase and mTOR, has antileukemic activity in AML. Leukemia 22(9):1698-1706

44. Minn AJ, Gupta GP, Siegel PM, Bos PD, Shu W, Giri DD, Viale A, Olshen AB, Gerald WL, Massague J (2005) Genes that mediate breast cancer metastasis to lung. Nature 436(7050):518-524

45. Catzavelos C, Bhattacharya N, Ung YC, Wilson JA, Roncari L, Sandhu C, Shaw P, Yeger H, Morava-Protzner I, Kapusta L, Franssen E, Pritchard KI, Slingerland JM (1997) Decreased levels of the cell-cycle inhibitor p27Kip1 protein: prognostic implications in primary breast cancer. Nat Med 3(2):227-230 